\title{
CHALLENGES AND OPPORTUNITY OF IN VITRO PROPAGATION OF PAULOWNIA TOMENTOSA STEUD FOR COMMERCIAL PRODUCTION IN NEPAL
}

\author{
Lila Bahadur Magar ${ }^{1}$, Nisha Shrestha ${ }^{1}$, Saraswoti Khadka ${ }^{1}$, Jay Raj Joshi ${ }^{1}$, Jibaraj Acharya ${ }^{1}$, Gaurav Chandra \\ Gyanwali $^{1}$, Bishnu Prasad Marasini ${ }^{1}$, Sabari Rajbahak ${ }^{2}$ and Niranjan Parajuli ${ }^{*}$,
}

${ }^{1}$ Department of Biotechnology, National College, Tribhuvan University, Naya Bazar, Kathmandu, Nepal. Tel: +977-1-4360096

${ }^{2}$ Department of Plant Resources, Thapathali, Kathmandu, Nepal. Tel.: +977-1-4261966

*Corresponding author: parajuliniranjan@yahoo.com

\begin{abstract}
Paulownia tomentosa Steud is a fast growing multipurpose tree. In vitro propagation using nodal explants of $P$. tomentosa was performed by manipulating amount of cytokinin and auxin in culture media. Shoot bud proliferation from explants were assessed in Murashige and Skoog (MS) medium supplemented with various amounts of hormones such as a) 0.5-2.5 mg/l benzylaminopurine (BAP) and 0.1 mg/l naphthalene acetic acid (NAA), b) 0.5-2.5 mg/l BAP and 0.5-2.5 mg/l kinetin (KN) and c) 0.5- $2.5 \mathrm{mg} / \mathrm{l} \mathrm{BAP}$ and $0.1 \mathrm{mg} / \mathrm{l}$ indole-3-acetic acid (IAA). In the present study, we found that hormone combination of BAP and NAA gave optimum growth results. MS medium enriched with 2.0 mg/l BAP and $0.1 \mathrm{mg} / \mathrm{l}$ IAA resulted a similar outcome but took 3-4 weeks with respect to the same medium enriched with $1.0 \mathrm{mg} / \mathrm{ml} \mathrm{BAP}$ and 0.1 $\mathrm{mg} / \mathrm{ml} \mathrm{NAA}$, which showed response within 2-3 weeks. Shoot length of 2.5-3.5 cm with 3-4 nodes and 8-12 leaves were obtained on MS medium supplemented with $1.0 \mathrm{mg} / \mathrm{l} \mathrm{BAP}$ and $0.1 \mathrm{mg} / \mathrm{l} \mathrm{NAA}$. The acclimatization of explants was done in a polyhouse at $20 \pm 5^{\circ} \mathrm{C}$ for $2-6$ weeks. Rooting was induced in sterile sand. Rooted plants were transferred to plastic bags containing mixture of soil, sand and compost in the ratio of $1: 1: 1$.

Besides aforementioned issues, there are several other challenges associated with in vitro propagation of $P$. tomentosa. Tissue culturing of the plant was established (90\%) on MS medium enriched with BAP and NAA and adapted ex vitro with surviving up to $80 \%$. People received an opportunity with this plant because it grows fast and can generate income in 10 years in comparison with others, but at the same time people also have been facing the challenges for plantation of $P$. tomentosa as government of Nepal does not formulate necessary national policies, legislations and regulatory frameworks in its favor. Thus, system should be developed to set royalty rate of $P$. tomentosa recognizing its lifetime value.
\end{abstract}

Keywords: Paulownia tomentosa; in vitro propagation; plant hormones.

\section{Introduction}

P. tomentosa (Empress tree) is a perennial, fast growing deciduous tree belonging to family Scrophulariaceae (Rout et al., 2001). Other species of Genus Paulownia includes $P$. fortunei, $P$. australis, $P$. elongata, P. tomentosa, $P$. kawakami, $P$. fargesi and P. albiphloea, P. catalpifolia and P. taiwaniana (Barton et al., 2007). It is native to China but has been commercially cultivated in Taiwan, Vietnam, Cambodia, Laos, Korea, Japan and North America (Burger et al., 1985).

P. tomentosa has multitude of economic benefits such as its timber is light but also strong, has high strength-to-weight ratio; a low shrinkage coefficient hence does not easily warp or crack, better insulation properties etc. (Chunchukov and Yancheva, 2015). Its charcoal is also used in high class fireworks and also in preparation of gun powder (Rout et $a l .$, 2001). Apart from that, they are valuable sources of secondary metabolites including flavonoids with high antioxidant activities and other pharmacological activities (Bahri and Bettaieb, 2013). Its bark is used in Chinese herbal medicine as remedies of infectious diseases such as gonorrhea, erysipelas, bronchitis, dysentery, acute enteritis, parotitis and, acute conjunctivitis (Bahri and Bettaieb, 2013). Therefore, mass propagation of Paulownia is considered essential (Akyildiz and Kol, 2010).

Micropropagation of tree species has many advantages to offer as it can be used to produce clonal plantlets for afforestation, woody biomass production resulting in genetic gain (Rout et al., 2001). This technique has been used in different tree species (Bonga and Aderkas, 1992).

Paulownia is propagated using either seeds or root cuttings traditionally. Propagation through seeds is considered unreliable due to impending disease and pest problem as well as poor germination and slow growth compared to root 
cuttings. Therefore, in vitro technique can be a potential alternative to mass production of shoot allows in a short period of time (Venkateswarlu et al., 2001). But there are also some inherent problems of in vitro culture such as: a) excessive callus growth at the base of explants and weakened axillary shoot proliferation; b) development of adventitious shoots on callus at the explant base; c) explant pushed out of the medium by emerging leaves; and d) difficulty in observation of cultures due to large sized leaves (Bochnia and Litwińczuk, 2012). Mass multiplication through nodal culture has been used previously (Ipekci et al., 2001).

Problems associated with in vitro culture can be relieved with different strategies. Different concentrations of sucrose and saccharides can modify development and quality of in vitro cultures of many species (George et al., 2008) but the concentrations of growth regulators required for maximal shoot production can differ among clones.

A high demand for planting material in domestic and international markets for afforestation and bioenergy production has necessitated the development of efficient micropropagation protocols for rapid and mass propagation of Paulownia (San Jose et al., 2014). With that question in mind, the current research was undertaken to determine the optimum concentration of both auxin and cytokinin, which would allow direct adventitious shoot proliferation of Paulownia explants for commercial production in Nepal. Further, we surveyed the regions where Paulownia tomentosa is planted and who have problems associated with their community.

\section{Material and Methods}

\section{Plant material collection and surface sterilization}

Actively growing juvenile shoots from axillary branches of two years old $P$. tomentos $a$ were collected locally during the month of April. The mother plant was selected from plantation site of farmer's field in Bhaktapur district, Nepal. Shoot tips with two to three nodes were taken as a source of explants. The plant materials were collected in a sterile glass container containing sterile distilled water and were transferred to laboratory. For the surface sterilization, the shoots were kept in running tap water for about $30 \mathrm{~min}$ with few drops of liquid detergent Tween 20. After washing with detergent the explants were thoroughly rinsed with distilled water for 4-5 times to remove any traces of detergent remaining in explants. After these treatments, explants were taken inside the laminar air flow for further sterilization. Explants were surface sterilized with freshly prepared $0.1 \%$ $\mathrm{w} / \mathrm{v}$ aqueous solution of mercuric chloride for $5 \mathrm{~min}$. Then, they were thoroughly rinsed for 3-4 times with sterilized distilled water to remove any traces of mercuric chloride (Rajbahak et al., 2014).

\section{Culture medium}

Single or double nodal explants were inoculated onto MS basal medium (Murashige and Skoog, 1962). Different concentrations of plant growth regulators were tested for shoot induction. MS medium was supplemented with 0.5 $\mathrm{mg} / \mathrm{l}, 1.0 \mathrm{mg} / \mathrm{l}, 2.0 \mathrm{mg} / \mathrm{l}, 2.5 \mathrm{mg} / \mathrm{l}$ and $5.0 \mathrm{mg} / \mathrm{l} \mathrm{BAP}$ and 0.1 $\mathrm{mg} / \mathrm{l}$ IAA, KN and NAA. $3 \%$ sucrose was used as carbon source and $\mathrm{pH}$ was adjusted to 5.8 before autoclave. The media was solidified using $0.8 \%$ agar and autoclaved at $121^{\circ} \mathrm{C}$ for $15 \mathrm{~min}$ (Rajbahak et al., 2014).

\section{Culture condition and in vitro shoots proliferation}

Before inoculation, explants were transferred to sterile Petri plates with the help of sterile forceps under strict aseptic conditions. The leaves were removed and single node 0.5 to $1.0 \mathrm{~cm}$ long was transferred to culture bottles containing MS medium with varying concentrations of growth hormones as described above. The cultures were incubated at $16 \mathrm{~h}$ photoperiod with light intensity of 3000 lux using florescent tube lights and temperature of $25 \pm 2^{\circ} \mathrm{C}$ for 4 weeks. After successful initiation of the shoot, newly formed shoots were excised and again leaf were trimmed and single nodes were sub-cultured on the medium with the same concentration of BAP and NAA. Sub-culture process was performed 4-5 times (Rajbahak et al., 2014).

\section{Sand rooting}

After 4-5 successive in vitro proliferation of explants, they were moved to polyhouse for acclimatization for a week. Plantlets were removed from bottles with the help of sterile forceps and washed with distilled water to remove media. Then, the plantlets were inserted into sand trays. The temperature and humidity of the polyhouse was maintained at $20 \pm 5 \mathrm{oC}$ and $80 \%$ humidity, respectively. Plants were assessed for rooting at 2-6 weeks. After six weeks plants were transferred into soil bags.

\section{Results}

The surface sterilization procedure is an important aspect of in vitro culture because contamination during tissue culture is a common problem. In this study, it was found that surface sterilization using tween 20 and $0.2 \%$ mercuric chloride yielded $90 \%$ aseptic cultures. Hence, the procedure was adapted as optimized procedure for sterilization of Paulownia explants.

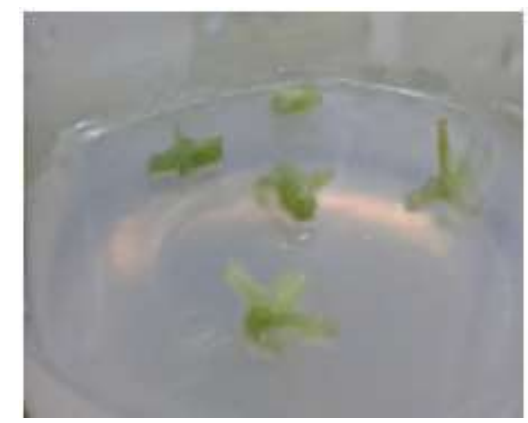

Fig. 1: Establishment of $P$. tomentosa explants in MS medium 


\section{Shoot proliferation}

The effect of different concentration of BAP and NAA is shown in Table 1. The efficacy of combination of growth hormones was assessed based on number of shoots induced after incubation. The number of shoots observed was found to be best in concentration of $1.0 \mathrm{mg} / \mathrm{l} \mathrm{BAP}$ and $0.1 \mathrm{mg} / \mathrm{l}$
NAA in short period of time (highlighted as bold letters in Table 1 and Fig. 2). The response was observed within 2-3 weeks. In comparison, MS medium supplemented with other hormones gave lesser number of shoots (Table 2 and $3)$.
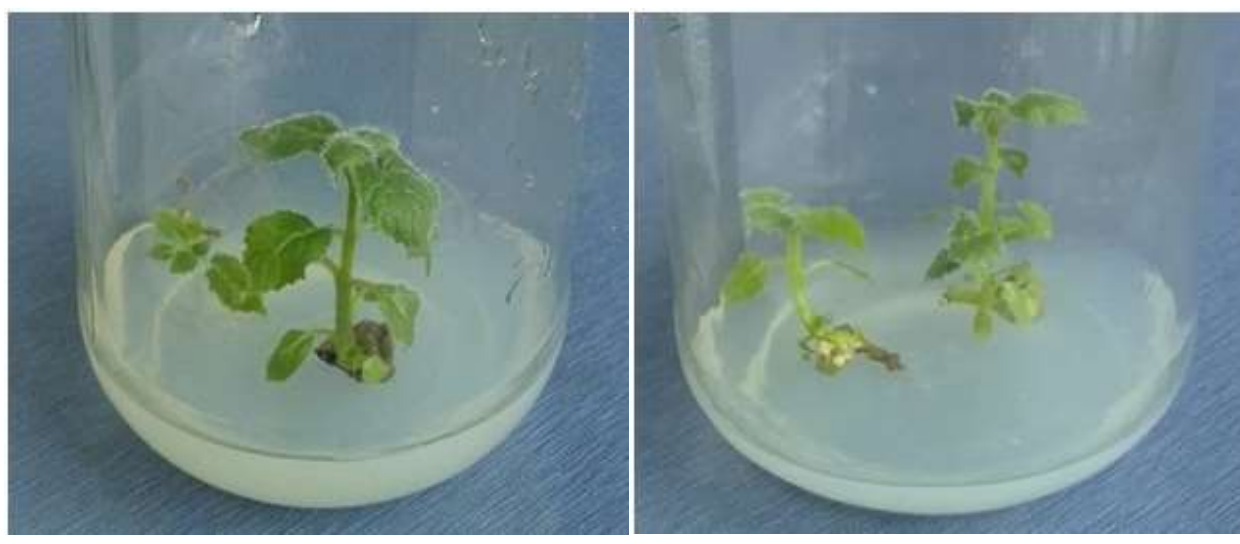

Fig. 2: Shoot proliferation of $P$. tomentosa explants in MS medium

Table 1: Effect of growth hormones (BAP+NAA) on shoot induction

\begin{tabular}{|l|l|l|l|l|l|}
\hline $\begin{array}{l}\text { Plant growth } \\
\text { regulators }\end{array}$ & $\begin{array}{l}\text { No of } \\
\text { culture } \\
\text { bottles } \\
\text { initiation }\end{array}$ & $\begin{array}{l}\text { No of days for shoot } \\
\text { No of node }\end{array}$ & No of leaves & $\begin{array}{l}\text { Height of } \\
\text { shoot(cm) }\end{array}$ \\
\hline BAP+NAA (mg/l) & & & & & \\
\hline $0.5+0.1$ & 5 & $21-28$ & $2-3$ & $6-7$ & $2.2-2.3$ \\
\hline $\mathbf{1 . 0 + 0 . 1}$ & $\mathbf{5}$ & $\mathbf{1 5 - 2 1}$ & $\mathbf{3 - 4}$ & $\mathbf{8 - 1 2}$ & $\mathbf{2 . 5 - 3 . 5}$ \\
\hline $1.5+0.1$ & 5 & $21-28$ & $2-3$ & $5-6$ & $1.8-1.9$ \\
\hline $2.0+0.1$ & 5 & $21-28$ & $2-3$ & $5-6$ & $8-9$ \\
\hline $2.5+0.1$ & 5 & $21-28$ & & $2-3$ & \\
\hline
\end{tabular}

Table 2: Effect of growth hormones $(\mathrm{BAP}+\mathrm{KN})$ on shoot induction

\begin{tabular}{|l|l|l|l|l|l|}
\hline $\begin{array}{l}\text { Plant growth } \\
\text { regulators }\end{array}$ & $\begin{array}{l}\text { No of culture } \\
\text { bottles }\end{array}$ & $\begin{array}{l}\text { No of days for shoot } \\
\text { initiation }\end{array}$ & No of node & No of leaves & $\begin{array}{l}\text { Height } \\
\text { shoot(cm) }\end{array}$ \\
\hline BAP+KN (mg/l) & & $21-28$ & & $3-4$ & \\
\hline $\mathbf{0 . 5 + 0 . 5}$ & $\mathbf{5}$ & $21-28$ & $2-3$ & $6-10$ & $\mathbf{2 - 3}$ \\
\hline $1.0+1.0$ & 5 & $21-28$ & $3-5$ & $7-8$ & $1.6-1.9$ \\
\hline $1.5+1.5$ & 5 & $21-28$ & $3-4$ & $8-10$ & $1.5-1.8$ \\
\hline $2.0+2.0$ & 5 & $21-28$ & $2-4$ & $6-8$ & $1.5-3.0$ \\
\hline $2.5+2.5$ & 5 & & & & $1.4-2.0$ \\
\hline
\end{tabular}


Table 3: Effect of growth hormones (BAP+IAA) on shoot induction

\begin{tabular}{|l|l|l|l|l|l|}
\hline $\begin{array}{l}\text { Plant growth } \\
\text { regulators }\end{array}$ & $\begin{array}{l}\text { No of culture } \\
\text { bottles }\end{array}$ & $\begin{array}{l}\text { No of days for shoot } \\
\text { initiation }\end{array}$ & No of node & No of leaves & $\begin{array}{l}\text { Height } \\
\text { shoot(cm) }\end{array}$ \\
\hline $\begin{array}{l}\text { BAP+IAA } \\
(\mathbf{m g} / \mathbf{l})\end{array}$ & & & & & \\
\hline $0.5+0.1$ & 5 & $21-28$ & $2-3$ & $8-10$ & $2-2.5$ \\
\hline $1.0+0.1$ & 5 & $21-28$ & $3-4$ & $8-11$ & $2-3$ \\
\hline $1.5+0.1$ & 5 & $21-28$ & $2-3$ & $8-10$ & $1.5-2.5$ \\
\hline $2.0+0.1$ & 5 & $21-28$ & $3-4$ & $8-12$ & $2.5-3.5$ \\
\hline $2.5+0.1$ & 5 & $21-28$ & $3-4$ & $8-10$ & $2.5-3.5$ \\
\hline
\end{tabular}

\section{Sand rooting}

The plantlets showed rooting after two weeks at $20 \pm 5^{\circ} \mathrm{C}$ polyhouse temperature and $80 \%$ humidity. Only $80 \%$ of the plants successfully developed roots. After six weeks, the plantlets were transferred to soil bag containing soil, sand and compost in the ratio of 1:1:1. (Fig. 3)

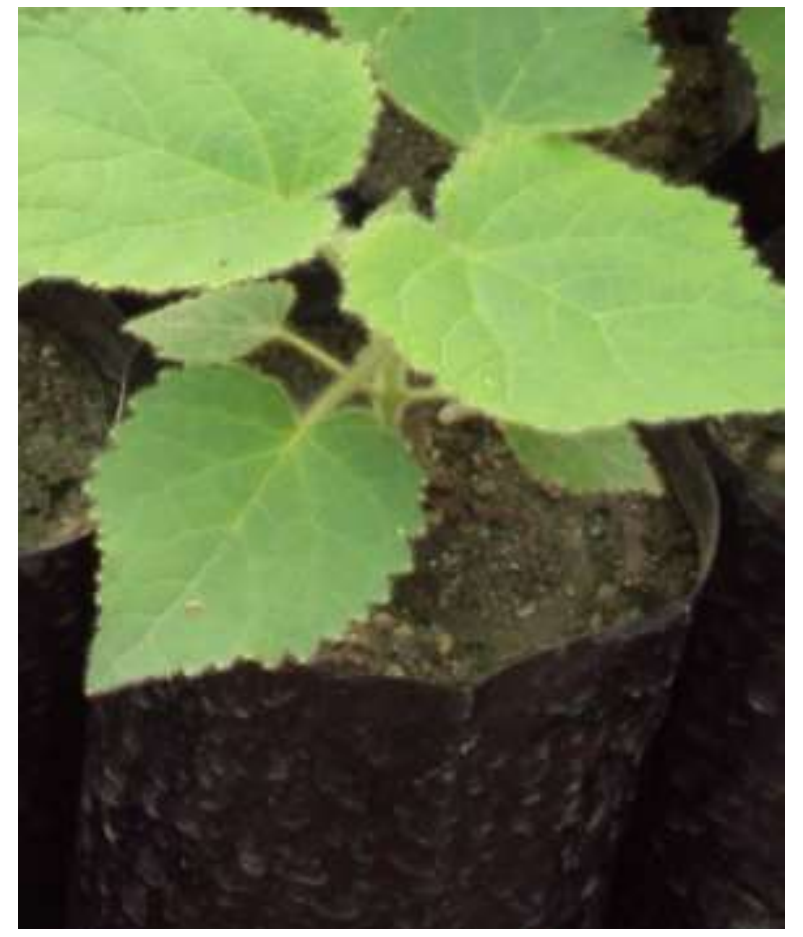

Fig. 3: P. tomentosa Steud (6 weeks old)

\section{Discussion}

In vitro approach to growing Paulownia has caught sufficient attention of many scientists in the past. Attempts have been made to culture Paulownia through in vitro seed culture (Shtereva et al., 2014). Similarly, tissue culture approach using Paulownia explants has also been performed (Bahri and Bettaieb, 2013; Rajbahak et al., 2014). In the present study, hormone combination of BAP and NAA gave optimum results. It was also found that the combination of hormone BAP and IAA at the concentration of 2.0 and $0.1 \mathrm{mg} / \mathrm{l}$ gave the similar result but on an average it took 3-4 weeks to obtain similar results compared to 1.0 $\mathrm{mg} / \mathrm{l} \mathrm{BAP}$ and $0.1 \mathrm{mg} / \mathrm{l} \mathrm{NAA}$.

One of the major factors that affect in vitro multiplication is attributed to somaclonal variations. Hence, the fidelity of clonal cultures needs to be assessed regularly. In the present study, it was observed visually by comparing the number of shoots and nodes developed during subsequent cultures. While not many changes were observed morphologically, molecular assessments can also be done using various markers. Studies by Rout et al. (2001) have used RAPD markers to assess genetic fidelity during subcultures to identify any genetic changes that have taken place. Presence of monomorphic bands in each subculture verified genetic fidelity.

Using the hormonal concentration as depicted in this study, mass propagation of Paulownia can be done in any tissue culture lab. Paulownia can be planted on barren lands or at places with higher deforestation rate. It can even be planted on community forests. Recently, its status as an invasive species has surfaced. It's mainly attributed to easy distribution of seeds to over long distances. Hence, use of sterile species that cannot produce viable seeds and fruits is proposed (Chunchukov and Yancheva, 2015).

Micropropagation technique as applied to agro-forestry is considered beneficial because genetically uniform clonal stock of high quality can be produced (Jagannathan, 1986). Therefore, an efficient vegetative propagation of Paulownia is essential and has many advantages over seedling production. Creation of hybrid and/or application of genetic engineering can be applied to shoot production for better variety (Ipekci and Gozukirmizi, 2003; Chunchukov and Yancheva, 2015). Furthermore, large leaves bearing trees like Paulownia can be effective means of carbon 
sequestration in community forests with potential economic returns.

Community forest in Nepal has been a successful program in terms of rehabilitating forest condition (Pokharel et al., 2009) since it was launched formally in 1978 (CFD, 2002). Rural Nepalese people are deprived of governmental facilities and majority of them depend fully on forest resources for their livelihood. Community forests have provided a platform to the people of community to enhance their livelihood by providing employments, safety nets and developing infrastructures (Chapagain et. al., 2009). Thus, the community based forest management approach has emerged as a successful program to improve the forest condition and livelihoods of people (Koirala et al., 2008). Our field visit to various districts showed that the community people are benefited by their community forest. However, there are some challenges often faced by the community people which includes cumbersome legal procedure, additional tax burden, high transaction cost for harvesting and trade, limited availability of quality planting material and uncertainty of timber supply (Subedi et al., 2014). Contribution of community forest and limited supply/availability of plantlets products to local communities are not recognized adequately by the national policies, legislations and regulatory frameworks (Chapagain and Banjade, 2009). Thus, system should be developed to set royalty rates of forest products for new tree species such as $P$. tomentosa recognizing its lifetime value.

\section{Acknowledgment}

This study was supported by the research project entitled 'In-vitro propagation of Paulownia tomentosa Steud. for commercial production and evaluate its carbon dioxide sequestration ability under changing climate' awarded to Dr. Niranjan Parajuli by Nepal Academy of Science and Technology (NAST) and supported by Asian Development Bank (ADB) under the grant MCCRMD (TA 7984 NEP).

\section{References}

Akyildiz M and Kol H (2010) Some technological properties and uses of paulownia (Paulownia tomentosa Steud.) wood. Journal of Environmental Biology 31(3): 351-355.

Bahri NB and Bettaieb T (2013) In vitro propagation of a forest tree Paulownia tomentosa (Thunb.) Steud. - A valuable medicinal tree species. Albanian Journal of Agricultural Sciences. 12(1): 37

Barton I, Nicholas I and Ecroyd C (2007) Paulownia. The Forest Research Bulletin. 231: 5-68

Bochnia E and Litwińczuk W (2012) Development of royal paulownia (Paulownia tomentosa Steud) in vitro shoot cultures under the influence of different saccharides. Acta Scientiarum Polonorum. 11(2): 3-13

Bonga J and Aderkas Pv (1992) In vitro culture of trees. Kluwer Academic Publishers, Dordrecht, The Netherland 72-125. DOI: $10.1007 / 978-94-015-8058-8$
Burger D, Liu L and Wu L (1985) Rapid micropropagation of Paulownia tomentosa. Hort Sci. 20: 760-761

CFD (2002) Database of the Community Forest Users Groups in Nepal. Community Forest Division, Department of Forest, Kathmandu, Nepal

Chapagain N and Banjade M (2009) Community Forestry as an Effective Institutional Platform for Local Development: Experiences from the Koshi Hills. Journal of Forest and Livelihood. 8(2). DOI: 10.3126/jfl.v8i2.2310

Chunchukov A and Yancheva S (2015) Micropropagation of Paulownia species and hybrids. First National Conference of Biotechnology. Sofia. 100

George EF, Hall MA and Klerk G-JD (2008) Micropropagation: Uses and Methods. Plant Propagation by Tissue Culture: Volume 1. The Background. George EF, Hall MA and Klerk G-JD. Dordrecht, Springer Netherlands: 29-64

Ipekci Z, Altinkut A, Kazan K, Bajrovic K and Gozukirmizi N (2001) High frequency plant regeneration from nodal explants of Paulownia elongata. Plant Biology. 3: 113115. DOI: $10.1055 / \mathrm{s}-2001-12903$

Ipekci Z and Gozukirmizi N (2003) Direct somatic embryogenesis and synthetic seed production from Paulownia elongata. Plant Cell Rep. 22: 16-24. DOI: 10.1007/s00299-0030650-5

Jagannathan (1986) Phenotypic and ploidy status of Paulownia tomentosa trees regenerated from culture hypocotyls. Plant cell, Tissue and organ culture. 7: 227-236. DOI: 10.1007/BF00037739

Koirala R, Giri K and Pokharel B (2008) Development and status of community forestry governance in Nepal.

Murashige T and Skoog F (1962) A revised medium for rapid growth and bioassays with tobacco tissue culture. Physiol Plant. 15: 473-497. DOI: 10.1111/j.13993054.1962.tb08052.x

Pokharel BK, Branney P, Nurse M and Malla YB (2009) Community Forestry: Conserving Forests, Sustaining Livelihoods and Strengthening Democracy. Journal of Forest and Livelihood. 6(2): 8-19

Rajbahak S, Chapagain N, Shrestha J and Basnet P (2014) Clonal propagation of Paulownia tomentosa Steud for commercial production. 36 Department of Plant Resource, Kathmandu, Nepal

Rout G, Reddy G and Das P (2001) Studies on in vitro clonal propagation of Paulownia tomentosa STEUD and Evaluation of Genetic Fidelity through RAPD Marker. Silvae Genetica. 50

San Jose MC, Cernadas M and Corredoira E (2014) Histology of the regeneration of Paulownia tomentosa (Paulowniaceae) by organogenesis. Rev Biol Trop. 62(2): 809-818. DOI: 10.15517/rbt.v62i2.10845

Shtereva L, Vassilevska-ivanova R, Karceva T and Kraptchev B (2014) Micropropagation of six Paulownia genotypes through tissue culture Journal of Central European Agriculture. 15(4): 147-156 
Subedi B, Ghimire P, Koontz A, Khanal S, Katwal P, Sthapit K and Mishra S (2014) Private Sector Involvement and Investment in Nepal's Forestry: Status, Prospects and Ways Forward. Multi Stakeholder Forestry Program (MSFP), Kathmandu
Venkateswarlu B, Mukhopadhyay J, Sreenivasan E and Kumar V (2001) Micropropagation of Paulownia fortuneii through in vitro axillary shoot proliferation. Indian J Exp Biol. 39(6): 594-599 